\title{
Dietary seaweed-derived polysaccharides improve growth performance of weaned pigs through maintaining intestinal barrier function and modulating gut microbial populations
}

Tiande Zou ${ }^{1,2}$, Jin Yang ${ }^{1,2}$, Xiaobo Guo ${ }^{1,2}$, Qin He $e^{1,2}$, Zirui Wang ${ }^{1,2}$ and Jinming You ${ }^{1,2^{*}}$ (i)

\begin{abstract}
Background: Seaweed-derived polysaccharides (SDP) represent an attractive source of prebiotic nutraceuticals for the food and animal husbandry industry. However, the mechanism by which SDP from Enteromorpha mediates pig growth are not fully understood. This study aimed to investigate how SDP supplementation influences the growth performance and intestinal health in weaned pigs.

Results: In Exp. 1, 240 weaned pigs were randomly assigned to four dietary treatments and fed with a basal diet or a basal diet containing 200, 400 or $800 \mathrm{mg} / \mathrm{kg} \mathrm{SDP}$, respectively, in a 21-day trial. Pigs on the $400 \mathrm{or} 800 \mathrm{mg} / \mathrm{kg}$ SDP-supplemented group had greater ADG and lower F/G ratio than those on the control group $(P<0.05)$. In Exp. 2, 20 male weaned pigs were randomly assigned to two treatments and fed with a basal diet (CON group) or a basal diet supplemented with $400 \mathrm{mg} / \mathrm{kg} \mathrm{SDP}$ (the optimum does from Exp. 1), in a 21-day trial. Pigs fed the SDP diet had greater ADG, the concentrations of serum IL- 6 and TNF- $a$ and the activities of glutathione peroxidase, superoxide dismutase and catalase $(P<0.05)$, and lower $F / G$, diarrhea rate, as well as serum $D$-lactate concentrations and diamine oxidase activity $(P<0.05)$. Moreover, dietary SDP supplementation enhanced secretory immunoglobulin A content, villus height and villous height: crypt depth ratio in small intestine, as well as the lactase and maltase activities in jejunum mucosa $(P<0.05)$. SDP supplementation elevated the mRNA levels of inflammatory responserelated genes (IL-6, TNF- $a, T L R 4, T L R 6$ and MyD88), and the mRNA and protein levels of ZO-1, claudin-1 and occludin in jejunum mucosa $(P<0.05)$. Importantly, SDP not only increased the Lactobacillus population but also reduced the Escherichia coli population in cecum $(P<0.05)$. Furthermore, SDP increased acetic acid and butyric acid concentrations in cecum $(P<0.05)$.
\end{abstract}

Conclusions: These results not only suggest a beneficial effect of SDP on growth performance and intestinal barrier functions, but also offer potential mechanisms behind SDP-facilitated intestinal health in weaned pigs.

Keywords: Intestinal health, Microflora, Pigs, Seaweed-derived polysaccharides

\footnotetext{
* Correspondence: youjinm@163.com

${ }^{1}$ Jiangxi Province Key Laboratory of Animal Nutrition, College of Animal Science and Technology, Jiangxi Agricultural University, Nanchang 330045, Jiangxi, China

${ }^{2}$ Jiangxi Province Key Innovation Center for Industry-Education Integration of High-Quality and Safety Livestock Production, Nanchang 330045, China
}

(c) The Author(s). 2021 Open Access This article is licensed under a Creative Commons Attribution 4.0 International License, which permits use, sharing, adaptation, distribution and reproduction in any medium or format, as long as you give appropriate credit to the original author(s) and the source, provide a link to the Creative Commons licence, and indicate if changes were made. The images or other third party material in this article are included in the article's Creative Commons licence, unless indicated otherwise in a credit line to the material. If material is not included in the article's Creative Commons licence and your intended use is not permitted by statutory regulation or exceeds the permitted use, you will need to obtain permission directly from the copyright holder. To view a copy of this licence, visit http://creativecommons.org/licenses/by/4.0/ The Creative Commons Public Domain Dedication waiver (http://creativecommons.org/publicdomain/zero/1.0/) applies to the data made available in this article, unless otherwise stated in a credit line to the data. 


\section{Introduction}

The intestinal epithelial barrier, mainly involves a single layer of epithelial cells that are interconnected by tight junctions, plays a pivotal role in controlling absorption of nutrients and preventing pathogens and toxins from entering the systemic circulation [1,2]. For neonatal mammals, the nutritional, physiological, and social stresses usually induce intestinal barrier disruption or enteropathy, which is accompanied by growth retardation and increasing the risk of diarrhea incidence [3-5]. Thus, developing a novel feeding strategy for improving intestinal epithelial barrier functions at early postnatal life stages has attracted considerable research interests worldwide.

Seaweed-derived polysaccharides (SDP) are one of the most abundant polysaccharides in marine organisms, which have been confirmed to exhibit wide variety of biological and pharmacological activities, including antioxidation [6], immunomodulation [7], anticoagulant activity [8] and gastrointestinal protection [9]. Collectively, these properties seem to impel SDP to serve as an effective dietary supplement for improving the growth performance and health of neonatal mammals. It has been shown that the benefits of seaweed polysaccharides (laminarin or fucoidan) as functional ingredients during the early stage may result from reduced intestinal inflammatory response and improved intestinal morphology [7, 10, 11]. Furthermore, Laminaria spp.-derived seaweed extract containing bioactive polysaccharides enhances growth performance and improves gut health in weaned pigs partly through the alteration of intestinal microbial environment and improvement of nutrient digestibility [12-14]. Enteromorpha is a kind of widespread green seaweed, which has been developed as a pharmaceutical product and healthcare food source [15]. Recent studies provide the new insights into the role of marine-derived polysaccharides from seaweed Enteromorpha in improving the gut health and antioxidant capacity in juvenile shrimps [16] and laying hens [6], respectively. However, to the best of our knowledge, the influence of SDP from Enteromorpha on health status and intestinal barrier functions in weaned pigs has not been investigated, and the underlying mechanisms still remain unclear.

Therefore, we hypothesize that SDP from Enteromorpha could improve the growth performance of weaned pigs, and the beneficial effects were related to the modulation of intestinal barrier integrity and function, immune response and changes of gut microbial fermentation. Specially, our objectives are to explain the underlying mechanism of SDP from Enteromorpha for improving intestinal health.

\section{Materials and methods}

All experimental procedures used in this study were approved by the Animal Care and Use Committee of Jiangxi Agricultural University (permit No. JXAULL20190098).

Exp. 1

\section{Animals, diets and experimental design}

Two hundred and forty pigs (Duroc $\times$ Landrace $\times$ Yorkshire), weaned at 24 days with an initial average body weight $(\mathrm{BW})$ of $6.79 \pm 0.04 \mathrm{~kg}$, were randomly assigned into one of four dietary treatments with six replicate pens per treatment (five barrows and five gilts per pen) on the basis of initial BW, sex and litter. The dietary treatments consisted of the basal diet (control group, CON) and basal diet supplemented with 200, 400 or $800 \mathrm{mg} / \mathrm{kg}$ SDP (provided by Qingdao Haida Biotechnology Co., Ltd., Qingdao, China). The SDP were produced from the seaweed Enteromorpha prolifera, which contains $4.82 \%$ protein, $2.9 \%$ moisture, $17487.6 \mathrm{mg} / \mathrm{kg}$ calcium, $15362.7 \mathrm{mg} / \mathrm{kg}$ magnesium, $24262.4 \mathrm{mg} / \mathrm{kg}$ potassium, $3.93 \mathrm{mg} / \mathrm{kg}$ arsenium, $1.22 \mathrm{mg} / \mathrm{kg}$ plumbum, and $0.86 \mathrm{mg} / \mathrm{kg}$ cadmium. The content of polysaccharides is more than $48 \%$. According to the analysis of polysaccharide composition by high performance liquid chromatography (HPLC), the SDP consisted of five monosaccharides including rhamnose (Rha), glucose (Glc), glucuronic acid (GlcA), xylose (Xyl) and galactose (Gal). The molar percentage of monosaccharides is Rha: 40.6\%, Glc: $38.2 \%$, GlcA: $9.3 \%$, Xyl: $6.3 \%$, Gal: $5.6 \%$. The basal diet was formulated to meet the National Research Council (2012)-recommended nutrient requirements for pigs at corresponding growth period, and the ingredient and nutrient composition were shown in Table 1. Pigs were fed isonitrogenous diets containing various levels of SDP. Although the additional SDP was added to the basal diet by substituting for the same amount of corn, the protein level is still low, which is basically consistent with protein in basal diet. All pigs were housed in a temperature-controlled room and had free access to water and feed throughout the trial. The experimental period lasted 21 days.

\section{Growth performance}

The pigs were weighed individually after $12-\mathrm{h}$ fasting in the morning of day 1 and day 22, and feed consumption per pen was recorded daily to calculated average daily feed intake (ADFI), average daily gain (ADG) and feed: gain $(F / G)$.

\section{Exp. 2}

\section{Animals, diets and experimental design}

A total of twenty healthy male pigs (Duroc $x$ Landrace $x$ Yorkshire), weaned at 24 days with an initial average 
Table 1 Ingredients and nutrient composition of the basal diet for piglets (as-fed basis) (Exp. 1 and Exp. 2)

\begin{tabular}{|c|c|c|c|}
\hline Ingredients & $\%$ & Nutrient composition & \\
\hline Extruded corn & 48.50 & Calculated composition & \\
\hline Soybean meal & 11.00 & Digestible energy, MJ/kg & 14.82 \\
\hline Extruded soybean & 10.00 & Crude protein, \% & 19.64 \\
\hline Broken rice & 9.00 & Calcium, \% & 0.81 \\
\hline Flour & 8.00 & Total phosphorus, $\%$ & 0.60 \\
\hline Whey powder & 6.00 & Available phosphorus, \% & 0.41 \\
\hline Soybean oil & 1.05 & Lysine, \% & 1.43 \\
\hline Fish meal & 2.50 & Methionine, \% & 0.54 \\
\hline Limestone & 1.00 & Methionine and cystine, \% & 0.83 \\
\hline Dicalcium phosphate & 0.90 & Threonine, \% & 0.98 \\
\hline $\mathrm{NaCl}$ & 0.30 & Tryptophan, \% & 0.20 \\
\hline L-Lysine $\mathrm{HCl}, 78 \%$ & 0.60 & Analysed composition & \\
\hline DL-Methionine, 99\% & 0.26 & Crude protein, \% & 18.69 \\
\hline L-Threonine, 98.5\% & 0.34 & Calcium, \% & 0.78 \\
\hline Choline chloride & 0.10 & Total phosphorus, $\%$ & 0.61 \\
\hline Vitamin premix ${ }^{a}$ & 0.05 & & \\
\hline Mineral premix ${ }^{b}$ & 0.40 & & \\
\hline Total & 100 & & \\
\hline
\end{tabular}

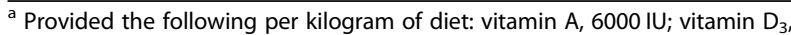
$480 \mathrm{IU}$; vitamin $\mathrm{E}$, $40 \mathrm{IU}$; vitamin $\mathrm{K}_{3}, 1.5 \mathrm{mg}$; thiamin, $3 \mathrm{mg}$; riboflavin, $6.4 \mathrm{mg}$; pyridoxine, $2.4 \mathrm{mg}$; vitamin $B_{12}, 0.04 \mathrm{mg}$; pantothenic acid, $10 \mathrm{mg}$; niacin, 14 $\mathrm{mg}$; biotin, $0.15 \mathrm{mg}$; folic acid, $0.2 \mathrm{mg}$

${ }^{b}$ Provided the following per kilogram of diet: Fe (as ferrous sulfate), $120 \mathrm{mg}$; $\mathrm{Cu}$ (as copper sulfate), $80 \mathrm{mg}$; $\mathrm{Mn}$ (as manganese sulfate), $60 \mathrm{mg} ; \mathrm{Zn}$ (as zinc sulfate), $120 \mathrm{mg}$; I (as potassium iodide), $0.3 \mathrm{mg}$; Se (as sodium selenite), $0.35 \mathrm{mg}$

body weight of $6.77 \pm 0.10 \mathrm{~kg}$, were randomly assigned into two dietary treatments $(n=10)$ based on their BW and litter, consisting of the basal diet $(\mathrm{CON})$ or the basal diet supplemented with $400 \mathrm{mg} / \mathrm{kg}$ SDP. This selection of SDP level in Exp. 2 was based on the results of Exp. 1, which suggested that $400 \mathrm{mg} / \mathrm{kg}$ SDP resulted in lower F/G ratio and higher ADG $(P<0.05)$ than $C O N$ group. The basal and experimental diet were the same as described for Exp. 1, belonging to the same production batch. All pigs were housed in individual metabolism cages $(0.7 \mathrm{~m} \times 1.5 \mathrm{~m})$ in a temperature-controlled conditions $\left(26 \pm 2{ }^{\circ} \mathrm{C}\right)$ with free access to food and water. The experimental period lasted for 21 days, and experimental procedures used were similar to those previously described for Exp. 1. Individual pig body weight was recorded after 12-hour fasting in the morning of day 1 and 22 , and feed consumption was recorded daily. ADFI, ADG and F/G were calculated. The pigs' diarrhea was observed at the same time of each morning throughout the experimental period as previously described [17]. The fecal consistency of each pig was assessed with a score from 0 to $3(0=$ normal feces, $1=$ pasty feces, $2=$ semiliquid feces, and $3=$ liquid feces). The occurrence of diarrhea was defined as daily fecal consistency score of $\geq 2$. Diarrhea rate per day in each treatment group was expressed as follows: diarrhea rate $(\%)=$ (number of pigs with diarrhea/total number of pigs) $\times 100$, and the cumulative rate of diarrhea was calculated.

\section{Sample collection and preparation}

At the end of the experiment, after 12-hour fasting, eight pigs with weight close to the average level of each group were selected for bleeding via the anterior vena cava. Blood samples were centrifuged at $3000 \times g$ for $15 \mathrm{~min}$ at $4{ }^{\circ} \mathrm{C}$ to collect serum. After blood collection, the same pigs were then euthanized by intravenous injection of pentobarbital sodium. The gastrointestinal tract was immediately removed and divided into duodenum, jejunum, ileum and cecum. Approximately $2 \mathrm{~cm}$ segments of the middle of duodenum, jejunum and ileum were isolated, washed and fixed in $4 \%$ paraformaldehyde for morphological analysis. The mucosa samples of small intestine were collected by scraping the intestinal wall with glass microscope slides, frozen in liquid nitrogen and stored at $-80^{\circ} \mathrm{C}$ until analysis. Finally, caecal digesta were snap frozen and stored at $-80^{\circ} \mathrm{C}$ for microbial population measurements.

\section{Serum parameters analysis}

Serum antioxidant parameters including glutathione peroxidase (GSH-Px) activity, superoxide dismutase (SOD) activity, catalase (CAT) activity, total antioxidant capacity (T-AOC), and malondialdehyde (MDA) concentration were determined by the commercial kits (Nanjing Jiancheng Institute of Bioengineering, Nanjing, China) according to the manufacturer's instructions. The level of interleukin (IL)-6, IL-10, IL-1 $\beta$, tumour necrosis factor (TNF)- $\alpha, D$-lactate and immunoglobulin (IgA, IgG and $(g M)$ and diamine oxidase (DAO) activity were measured using commercially porcine-specific ELISA kits (Beijing Winter Song Boye Biotechnology Co. Ltd., Beijing, China).

\section{Intestinal morphology}

The fixed intestinal segments were dehydrated, and then embedded in paraffin, and cut into $5-\mu \mathrm{m}$ thick sections. The sections were deparaffinized, rehydrated and stained with hematoxylin and eosin. At least four images per section and five sections from each pig were obtained. The villus height and crypt depth were determined on the images using an Olympus CK 40 microscope (Olympus Optical Company, Tokyo, Japan), and villi-crypt ratio (VCR) was calculated.

\section{Small intestine biochemical analysis}

The frozen small intestinal mucosa samples (approximately $0.5 \mathrm{~g}$ ) were weighed and homogenized in ice-cold 
physiological saline solution (1:9, weight/volume), and then were centrifuged at $3500 \times g$ for $15 \mathrm{~min}$ at $4{ }^{\circ} \mathrm{C}$ to collect the supernatant. The secreted immunoglobulin A (sIgA) content in each section of small intestine was determined by the porcine ELISA assay kit (mlbio Biotech, Shanghai, China), and the results were expressed as $\mathrm{mg}$ sIgA/g intestinal protein. The activities of disaccharidase (sucrase, lactase and maltase) in jejunal mucosa were analysed using commercial assay kits (Nanjing Jiancheng Bioengineering Institute), and expressed as on a per milligram protein basis. The protein concentration was determined by Pierce BCA Protein Assay kit (Thermo Scientific, Waltham, MA, USA).

\section{Quantitative real-time PCR ( $q R T-P C R)$ analysis}

Total RNA was extracted from the small intestinal mucosa using TRIzol reagent (Sigma-Aldrich, Saint Louis, MO, USA) in accordance with the manufacturer's instructions. The concentration and integrity of RNA was determined by nucleic-acid/protein analyzer (Beckman Coulter DU800, Beckman Coulter Inc., Fullerton, CA, USA) and $1 \%$ agarose gel electrophoresis, respectively. Reverse transcription reactions were conducted using iScript $^{\text {tm }}$ cDNA Synthesis Kit (Bio-Rad, Hercules, CA, USA). qRT-PCR was performed on the CFX96 RT-PCR Detection System (Bio-Rad) as described previously [17]. The relative mRNA expression of target genes was calculated and normalized with $\beta$-actin reference using the method of $2^{-\Delta \Delta C T}$ [18]. The used primer sequences are shown in Table 2.

\section{Immunoblotting analysis}

Immunoblotting analysis was performed as previously described [19]. Briefly, protein extracts from jejunal mucosa were separated by $10 \%$ SDS-PAGE and then transferred to PVDF membrane. Membranes were blocked with $5 \%$ non-fat dry milk in TBST for $1 \mathrm{~h}$ and overnight incubated at $4{ }^{\circ} \mathrm{C}$ with the primary antibodies against zonula occludens-1 (ZO-1), claudin-1, occludin, and $\beta$-actin (Proteintech, Chicago, IL, USA), followed by incubation with HRP-linked secondary antibody anti-rabbit IgG or anti-mouse IgG (Cell Signaling Technology, Danvers, USA) in TBST for $1 \mathrm{~h}$ at room temperature. Finally, membranes were visualized using Bio-Rad ChemiDoc ${ }^{\mathrm{Tw}}$ imaging system (Bio-Rad). Band density of target protein was quantified after normalization to $\beta$-actin.

\section{Quantification of microbial population}

Bacterial DNA was extracted from caecal digesta using the Stool DNA kit (Omega Bio-Tek, Norcross, GA, USA) in accordance with the manufacturer's instruction. The microbial qRT-PCR was analysis on the CFX-96
RT-PCR Detection System (Bio-Rad) as described previously [20]. Briefly, the number of total bacteria was determined using SYBR Premix Ex Taq reagents (TaKaRa Biotechnology, Dalian, China), and the PCR system was composed of $12.5 \mu \mathrm{L}$ SYBR Premix Ex Taq $(2 \times), 1 \mu \mathrm{L}$ of forward and $1 \mu \mathrm{L}$ of reverse primers $(100 \mathrm{nmol} / \mathrm{L}), 9.5 \mu \mathrm{L}$ $\mathrm{ddH}_{2} \mathrm{O}$ and $1 \mu \mathrm{L}$ cDNA. Cycling conditions were as follows: $95^{\circ} \mathrm{C}$ for $30 \mathrm{~s}$, followed forty cycles of denaturation at $95^{\circ} \mathrm{C}$ for $5 \mathrm{~s}$, annealing at $60^{\circ} \mathrm{C}$ for $30 \mathrm{~s}$ and extension at $72{ }^{\circ} \mathrm{C}$ for $60 \mathrm{~s}$. The number of Lactobacillus, Bacillus, E. coli and Bifidobacterium were measured using PrimerScript $^{\mathrm{m}}$ PCR kit (TaKaRa), and the PCR system was composed of $8 \mu \mathrm{L}$ RealMasterMix (2.5x), $1 \mu \mathrm{L}$ of forward and $1 \mu \mathrm{L}$ of reverse primers $(100 \mathrm{nmol} / \mathrm{L}), 1 \mu \mathrm{L} 20 \times$ probe enhancer solution, $0.3 \mu \mathrm{L}$ probe $(100 \mathrm{nmol} / \mathrm{L})$, $1 \mu \mathrm{L}$ DNA and $7.7 \mu \mathrm{L} \mathrm{dd}_{2} \mathrm{O}$. Cycling conditions were as follows: $95^{\circ} \mathrm{C}$ for $2 \mathrm{~min}$, followed fifty cycles of denaturation at $95^{\circ} \mathrm{C}$ for $15 \mathrm{~s}$, annealing at $60^{\circ} \mathrm{C}$ for $30 \mathrm{~s}$ and extension at $72{ }^{\circ} \mathrm{C}$ for $50 \mathrm{~s}$. For the quantification of bacteria in test samples, specific standard curves were generated by constructing standard plasmids as presented by Chen et al. [21]. The bacterial copies were transformed $\left(\log _{10}\right)$ before statistical analysis. The used primers and probes were listed in Table 3.

\section{Determination of caecal short-chain fatty acid (SCFAs) concentrations}

The concentration of main SCFAs in caecal digesta was determined by gas chromatography as previously described [22]. Digesta samples were weighed and then centrifuged to obtain the supernatants after adding distilled water. The supernatant $(1 \mathrm{~mL})$ was mixed with 0.2 $\mathrm{mL}$ metaphosphoric acid, followed incubation at $4{ }^{\circ} \mathrm{C}$ for $30 \mathrm{~min}$. The mixture was centrifuged at $12,000 \times g$ for $10 \mathrm{~min}$ at $4{ }^{\circ} \mathrm{C}$ and $1 \mu \mathrm{L}$ of the supernatant was measured by injection into the gas chromatograph system (GC2014, Shimadzu Corporation, Kyoto, Japan).

\section{Statistical analysis}

The experimental design of Exp.1 was a completely randomized block design based on initial BW, sex and litter. For the growth performance in Exp. 1, data were analyzed using the GLM procedure of SAS (SAS Institute Inc., Cary, NC, USA), with pen as the experimental unit. Significant differences among groups were determined by Duncan's multiple range test. Mortality rate of pigs were analyzed using chi-square test. For all other variables in Exp. 2, data were analyzed by using an unpaired two-tailed Student's $t$-test, with the selected pig as the experimental unit. Results were presented as means and standard error (SE) except for the mortality rate of pigs as percentage. A significant difference was considered as $P<0.05$. 
Table 2 Nucleotide sequences of primers used to measure targeted genes (Exp. 2)

\begin{tabular}{|c|c|c|c|}
\hline Gene symbols & Nucleotide sequence of primers $\left(5^{\prime} \rightarrow 3^{\prime}\right)$ & Product length, bp & Accession No. \\
\hline$\beta$-actin & $\begin{array}{l}\text { F: TCTGGCACCACACCTTCT } \\
\text { R: TGATCTGGGTCATCTTCTCAC }\end{array}$ & 78 & XM_021086047.1 \\
\hline TLR2 & $\begin{array}{l}\text { F: ACGTATCCATCAATGAACACTGC } \\
\text { R: AAGGGTGCAGTCATCAAACTC }\end{array}$ & 146 & NM_213761.1 \\
\hline TLR4 & $\begin{array}{l}\text { F: TCAGTTCTCACCTTCCTCCTG } \\
\text { R: GTTCATTCCTCACCCAGTCTTC }\end{array}$ & 121 & GQ503242.1 \\
\hline TLR6 & $\begin{array}{l}\text { F: TCTCATGGCACAGCGAACTT } \\
\text { R: ACATCATCCTCTTCAGCGACT }\end{array}$ & 123 & NM_213760.2 \\
\hline MyD88 & $\begin{array}{l}\text { F: GGTGCCAGGCAGGACATC } \\
\text { R: GGCAGCTGGAACAGACCAA }\end{array}$ & 68 & NM_001099923.1 \\
\hline IL-6 & $\begin{array}{l}\text { F: GACAAAGCCACCACCCCTAA } \\
\text { R: CTCGTTCTGTGACTGCAGCTTATC }\end{array}$ & 69 & M80258.1 \\
\hline$I L-1 \beta$ & $\begin{array}{l}\text { F: TCTGCCTGTACCCCAACTG } \\
\text { R: CCAGGAAGACGGGCTITTG }\end{array}$ & 63 & NM214055.1 \\
\hline TNF- $a$ & $\begin{array}{l}\text { F: CGTGAAGCTGAAAGACAACCAG } \\
\text { R: GATGGTGTGAGTGAGGAAAACG }\end{array}$ & 121 & EU682384.1 \\
\hline $\operatorname{lL}-10$ & $\begin{array}{l}\text { F: GACCAGATGGGCGACTTGTT } \\
\text { R: TGCCTTCGGCATTACGTCTT }\end{array}$ & 120 & NM_214041.1 \\
\hline $\mathrm{ZO}-1$ & $\begin{array}{l}\text { F: GAGGATGGTCACACCGTGGT } \\
\text { R: GGAGGATGCTGTTGTCTCGG }\end{array}$ & 169 & XM_021098896.1 \\
\hline Claudin-1 & $\begin{array}{l}\text { F: TCAATACAGGAGGGAAGCCAT } \\
\text { R: ATATTTAAGGACCGCCCTCTCC }\end{array}$ & 91 & NM_001244539.1 \\
\hline Occludin & $\begin{array}{l}\text { F: CAGGTGCACCCTCCAGATTG } \\
\text { R: TGGACTTCAAGAGGCCTGG }\end{array}$ & 111 & NM_001163647.2 \\
\hline
\end{tabular}

TLR toll like receptor, MyD88 myeloid differentiation factor 88, IL-6 interleukin-6, IL-1 $\beta$ interleukin-1 $\beta$, TNF- $a$ tumor necrosis factor a, IL-10 interleukin-10, TGF- $\beta 1$ transforming growth factor- $\beta 1$, ZO-1 zonula occludens-1

\section{Results}

\section{Growth performance and diarrhea index (Exp. 1)}

As shown in Table 4, there were no significant differences in ADFI between the pigs fed the CON diet and the SDP diets. However, dietary supplementation with 400 or $800 \mathrm{mg} / \mathrm{kg}$ SDP increased ADG $(P<0.05)$ and decreased $F / G$ ratio $(P<0.05)$ compared with the CON group. No significant difference in growth performance between the pigs fed the CON diet and $200 \mathrm{mg} / \mathrm{kg}$ SDP-supplemented diet. Moreover, mortality rate of pigs was decreased numerically by SDP supplements $(6.67 \%$ in CON, $3.33 \%, 1.67 \%$ and $1.67 \%$, respectively, in 200,400 and $800 \mathrm{mg}$ SDP).

Table 3 Primer and probe sequences used for real-time PCR

\begin{tabular}{|c|c|c|}
\hline Items & Primer and probe sequence $\left(5^{\prime} \rightarrow 3^{\prime}\right)$ & Product length, bp \\
\hline Total bacteria & $\begin{array}{l}\text { F: ACTCCTACGGGAGGCAGCAG } \\
\text { R: ATTACCGCGGCTGCTGG }\end{array}$ & 200 \\
\hline \multirow[t]{2}{*}{ Lactobacillus } & $\begin{array}{l}\text { F: GAGGCAGCAGTAGGGAATCTTC } \\
\text { R: CAACAGTTACTCTGACACCCGTTCTTC }\end{array}$ & 126 \\
\hline & P: AAGAAGGGTTTCGGCTCGTAAAACTCTGTT & \\
\hline \multirow[t]{2}{*}{ Bifidobacterium } & $\begin{array}{l}\text { F: CGCGTCCGGTGTGAAAG } \\
\text { R: CTTCCCGATATCTACACATTCCA }\end{array}$ & 121 \\
\hline & P: ATTCCACCGTTACACCGGGAA & \\
\hline \multirow[t]{2}{*}{ Bacillus } & $\begin{array}{l}\text { F: GCAACGAGCGCAACCCTTGA } \\
\text { R: TCATCCCCACCTTCCTCCGGT }\end{array}$ & 92 \\
\hline & P: CGGTTTGTCACCGGCAGTCACCT & \\
\hline \multirow[t]{2}{*}{ Escherichia coli } & $\begin{array}{l}\text { F: CATGCCGCGTGTATGAAGAA } \\
\text { R: CGGGTAACGTCAATGAGCAAA }\end{array}$ & 96 \\
\hline & P: AGGTATTAACTTTACTCCCTTCCTC & \\
\hline
\end{tabular}


Table 4 Effects of dietary seaweed-derived polysaccharides (SDP) on growth performance of weaned pigs (Exp. 1)

\begin{tabular}{|c|c|c|c|c|c|}
\hline \multirow[t]{2}{*}{ Items } & \multirow[t]{2}{*}{ CON } & \multicolumn{3}{|c|}{ Dietary SDP, mg/kg } & \multirow[t]{2}{*}{$P$-value } \\
\hline & & 200 & 400 & 800 & \\
\hline Initial BW, kg & $6.77 \pm 0.09$ & $6.75 \pm 0.08$ & $6.80 \pm 0.09$ & $6.87 \pm 0.09$ & 0.779 \\
\hline Final BW, kg & $12.24 \pm 0.18^{b}$ & $12.65 \pm 0.26^{b}$ & $13.24 \pm 0.13^{\mathrm{a}}$ & $13.47 \pm 0.17^{\mathrm{a}}$ & 0.001 \\
\hline$A D F I, g$ & $386.1 \pm 5.3$ & $392.3 \pm 13.0$ & $409.4 \pm 7.7$ & $418.1 \pm 13.7$ & 0.150 \\
\hline$A D G, g$ & $260.5 \pm 7.3^{b}$ & $281.1 \pm 10.3^{b}$ & $306.7 \pm 4.7^{a}$ & $314.2 \pm 5.5^{\mathrm{a}}$ & $<0.001$ \\
\hline$F / G$ & $1.49 \pm 0.04^{b}$ & $1.47 \pm 0.03^{b}$ & $1.34 \pm 0.02^{\mathrm{a}}$ & $1.36 \pm 0.05^{\mathrm{a}}$ & 0.004 \\
\hline Mortality, \% & 6.67 & 3.33 & 1.67 & 1.67 & 0.376 \\
\hline
\end{tabular}

$A D F I$ average daily feed intake; $A D G$ average daily gain; $F / G$ feed: gain

$n=6$ for each group ${ }^{a, b}$ Mean values with unlike superscript letters were significantly different $(P<0.05)$

\section{Growth performance (Exp. 2)}

As shown in Table 5, the SDP-supplemented pigs had greater ADG $(P<0.05)$ and lower $\mathrm{F} / \mathrm{G}$ ratio $(P<0.05)$ compared to those in the CON group. No significant difference in ADFI was observed between the two groups. In addition, pigs fed the SDP diet had lower diarrhea rates $(P<0.05)$ than those fed the $\mathrm{CON}$ diet during the overall period. There was no mortality in either group.

\section{Antioxidant capacity (Exp. 2)}

The serum antioxidant parameter results are shown in Table 6. Dietary SDP supplementation increased the activities of GSH-Px, SOD and CAT in serum $(P<0.05)$. Meanwhile, pigs fed SDP diet tended to have a increased $\mathrm{T}$-AOC activity and reduced MDA content in serum compared with those in the CON group $(P<0.10)$.

\section{Immune indices (Exp. 2)}

After dietary SDP inclusion, higher IL- 6 and TNF- $\alpha$ concentrations in the serum were observed relative to $\mathrm{CON}$ group $(P<0.05)$. Meanwhile, pigs on the SDP group tended to have a increased IgG content $(P=0.090)$ compared to those on the CON group. Dietary SDP supplementation increased mucosal sIgA content in all of the selected intestinal segments $(P<0.05)$ (Table 7).

Table 5 Effects of dietary seaweed-derived polysaccharides (SDP) on growth performance and diarrhea rate of weaned pigs (Exp. 2)

\begin{tabular}{llll}
\hline \multirow{2}{*}{ Items } & \multicolumn{2}{l}{ Dietary treatment } & P-value \\
\cline { 2 - 3 } & CON & SDP & \\
\hline Initial BW, kg & $6.73 \pm 0.11$ & $6.81 \pm 0.10$ & 0.597 \\
Final BW, kg & $12.85 \pm 0.09$ & $13.52 \pm 0.18$ & 0.005 \\
ADFl, g & $415.7 \pm 8.6$ & $431.8 \pm 7.6$ & 0.185 \\
ADG, g & $291.6 \pm 4.6$ & $319.7 \pm 4.8$ & 0.001 \\
F/G & $1.43 \pm 0.02$ & $1.35 \pm 0.02$ & 0.025 \\
Diarrhea rate, \% & $7.86 \pm 0.56$ & $4.51 \pm 1.01$ & 0.036 \\
\hline $\begin{array}{l}\text { ADFI average daily feed intake; } A D G \text { average daily gain; F/G feed: gain } \\
n=8 \text { for each group }\end{array}$ &
\end{tabular}

Intestinal morphology (Exp. 2)

The data of intestinal morphology were shown in Table 8. In the duodenum, dietary supplementation of SDP significantly increased villous height and the VCR index and decreased crypt depth compared with the control group $(P<0.05)$. In the Jejunum, pigs fed the SDP diet had higher villus height and VCR index than those fed the CON diet $(P<0.05)$. A similar histomorphologic change was observed in the ileum.

The activities of disaccharidase in jejunal mucosa (Exp. 2) As shown in Table 9, pigs fed the SDP diet had markedly increased the activities of lactase and maltase in jejunal mucosa compared with those fed the CON diet $(P<0.05)$. However, no significant difference in sucrase activity was observed between the two groups.

\section{Serum diamine oxidase activity and $D$-lactate content (Exp. 2)}

As shown in Fig. 1, dietary supplementation with SDP significantly decreased the DAO activity and $D$-lactate content in serum compared with the CON group $(P<$ 0.05).

\section{Intestinal inflammatory response and barrier functions related genes expression (Exp. 2)}

As shown in Fig. 2, dietary supplementation of SDP increased the mRNA abundance of $I L-6, T N F-\alpha$, toll like

Table 6 Effects of dietary seaweed-derived polysaccharides (SDP) on the serum antioxidant status of weaned pigs (Exp. 2)

\begin{tabular}{llll}
\hline Items & \multicolumn{2}{l}{ Dietary treatment } & P-value \\
\cline { 2 - 3 } & CON & SDP & \\
\hline GSH-Px, U/mL & $352.45 \pm 18.33$ & $438.38 \pm 22.07$ & 0.024 \\
SOD, U/mL & $60.17 \pm 3.64$ & $77.80 \pm 1.96$ & 0.005 \\
CAT, U/mL & $11.83 \pm 0.96$ & $15.98 \pm 0.85$ & 0.006 \\
T-AOC, U/mL & $4.73 \pm 0.16$ & $5.23 \pm 0.17$ & 0.054 \\
MDA, nmol/mL & $5.05 \pm 0.33$ & $4.05 \pm 0.27$ & 0.064 \\
\hline
\end{tabular}

GSH-Px glutathione peroxidase; SOD superoxide dismutase; CAT catalase; $T$ $A O C$ total antioxidant capacity; MDA malondialdehyde $n=8$ for each group 
Table 7 Effects of dietary seaweed-derived polysaccharides (SDP) on the immune responses of weaned pigs (Exp. 2)

\begin{tabular}{|c|c|c|c|}
\hline \multirow[t]{2}{*}{ Items } & \multicolumn{2}{|c|}{ Dietary treatment } & \multirow[t]{2}{*}{$P$-value } \\
\hline & $\mathrm{CON}$ & SDP & \\
\hline \multicolumn{4}{|l|}{ Serum } \\
\hline $\operatorname{lgG}, g / L$ & $19.63 \pm 0.86$ & $21.98 \pm 0.78$ & 0.090 \\
\hline $\lg A, g / L$ & $1.25 \pm 0.09$ & $1.30 \pm 0.05$ & 0.653 \\
\hline $\lg M, g / L$ & $2.34 \pm 0.04$ & $2.39 \pm 0.06$ & 0.540 \\
\hline $\mathrm{IL}-6, \mathrm{pg} / \mathrm{mL}$ & $127.14 \pm 4.98$ & $159.31 \pm 7.35$ & 0.003 \\
\hline IL-10, pg/mL & $14.65 \pm 2.47$ & $17.36 \pm 1.23$ & 0.342 \\
\hline $\mathrm{IL}-1 \beta, \mathrm{pg} / \mathrm{mL}$ & $31.68 \pm 3.32$ & $33.48 \pm 2.28$ & 0.662 \\
\hline TNF-a, pg/mL & $57.61 \pm 3.90$ & $70.76 \pm 4.56$ & 0.046 \\
\hline \multicolumn{4}{|c|}{ Mucosal slgA, mg/g protein } \\
\hline Duodenum & $3.35 \pm 0.66$ & $5.56 \pm 0.74$ & 0.043 \\
\hline Jejunum & $4.78 \pm 0.50$ & $8.14 \pm 0.53$ & $<0.001$ \\
\hline Ileum & $5.68 \pm 0.46$ & $9.04 \pm 0.61$ & 0.001 \\
\hline
\end{tabular}

$\operatorname{lgG}$ immunoglobulin G; $\lg A$ immunoglobulin $\mathrm{A}$; $\lg M$ immunoglobulin $\mathrm{M}$; IL6 interleukin-6; IL-10 interleukin-10; IL-1 $\beta$ interleukin-1 $\beta$; TNF- $\alpha$ tumour necrosis factor-a; slgA secretory immunoglobulin $A$

$n=8$ for each group

receptor (TLR) 4, TLR6 and myeloid differentiation factor $88(M y D 88)$ in the jejunum mucosa of pigs $(P<0.05)$. In addition, the expression levels of several critical genes related to intestinal barrier functions were shown in Fig. 3. Compared to the CON group, SDP-supplemented pigs had higher occludin mRNA expression level in the duodenum mucosa $(P<0.05)$. Dietary SDP supplementation also elevated the mRNA expression levels of $Z O-1$, claudin- 1 and occludin in the jejunum mucosa $(P<0.05)$, and elevated the mRNA expression levels of claudin-1 and occludin in the ileum mucosa $(P<0.05)$. Consistently,

Table 8 Effects of dietary seaweed-derived polysaccharides (SDP) on intestinal morphology of weaned pigs (Exp. 2)

\begin{tabular}{|c|c|c|c|}
\hline \multirow[t]{2}{*}{ Items } & \multicolumn{2}{|c|}{ Dietary treatment } & \multirow[t]{2}{*}{$P$-value } \\
\hline & CON & SDP & \\
\hline \multicolumn{4}{|c|}{ Villus height, $\mu \mathrm{m}$} \\
\hline Duodenum & $212.78 \pm 14.37$ & $277.50 \pm 11.06$ & 0.003 \\
\hline Jejunum & $197.18 \pm 10.81$ & $281.56 \pm 11.99$ & $<0.001$ \\
\hline lleum & $168.12 \pm 4.89$ & $243.74 \pm 10.90$ & $<0.001$ \\
\hline \multicolumn{4}{|c|}{ Crypt depth, $\mu \mathrm{m}$} \\
\hline Duodenum & $105.24 \pm 3.49$ & $91.47 \pm 2.83$ & 0.008 \\
\hline Jejunum & $96.75 \pm 4.91$ & $87.59 \pm 2.25$ & 0.121 \\
\hline lleum & $76.91 \pm 3.17$ & $67.88 \pm 3.05$ & 0.059 \\
\hline \multicolumn{4}{|l|}{ VCR } \\
\hline Duodenum & $2.05 \pm 0.18$ & $3.06 \pm 0.17$ & 0.001 \\
\hline Jejunum & $2.07 \pm 0.15$ & $3.24 \pm 0.18$ & $<0.001$ \\
\hline Ileum & $2.21 \pm 0.09$ & $3.67 \pm 0.28$ & 0.001 \\
\hline
\end{tabular}

$V C R$ villus height: crypt depth ratio

$n=8$ for each group
Table 9 Effects of dietary seaweed-derived polysaccharides (SDP) on the activities of disaccharidases in jejunal mucosa of weaned pigs (Exp. 2)

\begin{tabular}{llll}
\hline Items & \multicolumn{2}{l}{ Dietary treatment } & P-value \\
\cline { 2 - 3 } & CON & SDP & \\
\hline Lactase, $U / m g$ protein & $104.97 \pm 3.28$ & $118.40 \pm 7.58$ & 0.008 \\
Sucrase, $U / m g$ protein & $75.60 \pm 4.40$ & $91.05 \pm 8.33$ & 0.199 \\
Maltase, $\mathrm{U} / \mathrm{mg}$ protein & $144.41 \pm 9.48$ & $240.46 \pm 11.19$ & 0.001 \\
\hline$n=8$ for each group & & &
\end{tabular}

the protein expressions of ZO-1, claudin-1 and occludin in the jejunum mucosa were increased by SDP supplementation $(P<0.05)$.

Intestinal microbial populations and metabolites (Exp.2) As shown in Fig. 4, dietary SDP supplementation significantly increased the Lactobacillus population and reduced the Escherichia coli population in the cecum of pigs $(P<0.05)$. Moreover, compared to the CON group, SDP-supplemented pigs had higher acetic acid and butyric acid concentrations in the cecal digesta $(P<0.05)$.

\section{Discussion}

In recent years, natural bioactive polysaccharides have attracted extensive attention worldwide since their usefulness in regulating the gut health and metabolism [23]. Seaweeds are considered a potential source of useful metabolites and bioactive polysaccharide compounds, with wide variety of biological and physiological activities [24]. The results of the present study first showed that proper dietary Enteromorpha polysaccharides supplementation improved the growth performance in weaned pigs, which is similar to previous report in juvenile shrimp [16]. Another intriguing discovery in the present study is that the occurrence of diarrhea in pigs fed SDPsupplemented diet was significantly decreased. In order to clarify the mechanism of health-promoting effect of dietary SDP, the metabolic and intestinal responses of weaned pigs to the SDP diet were further investigated.

Oxidative stress, defined as the disequilibrium between the generation of reactive oxygen species (ROS) and the antioxidant network, is considered as an essential pathogenic factor in the development of gastrointestinal mucosal diseases [25]. Weaning is the most severe early-life stress for pigs, resulting in the damage of antioxidant system [26]. The complex enzymatic antioxidant defense system including GSH-Px, SOD and CAT are involved in protecting the organism from the damaging effects of ROS [27]. In detail, SOD plays a crucial role in scavenging superoxide radicals, whereas CAT is mainly responsible for eliminating organic hydroxyl radicals [28]. The current study showed that dietary SDP supplementation enhanced the activities of SOD, CAT and GSH-Px in 

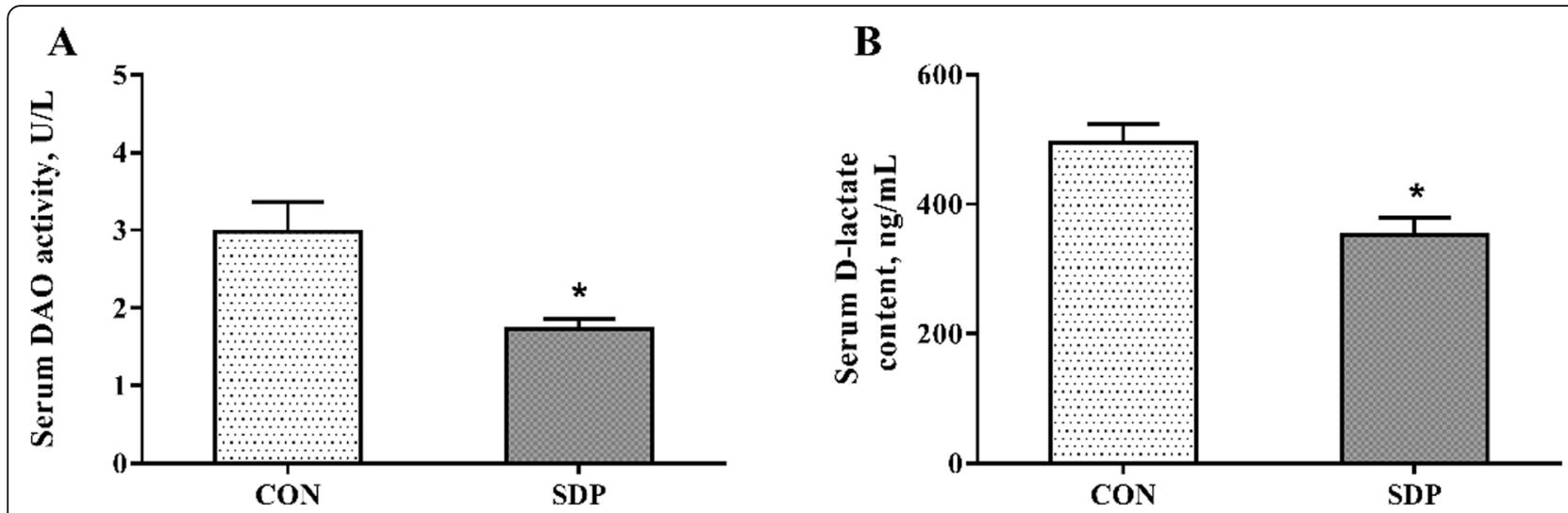

Fig. 1 Effects of dietary seaweed-derived polysaccharides (SDP) on serum diamine oxidase (DAO) activity and D-lactate content in weaned pigs. a serum DAO activity; b serum D-lactate content. Data are expressed as means $\pm \mathrm{SEM}, n=8,{ }^{*} P<0.05$

serum, which was similar to the previous study in laying hens [6]. The improved antioxidant defense systems function of weaned pigs by dietary SDP might also contribute to the improvement in growth performance in the present study.

Previous study demonstrated that Enteromorpha-derived polysaccharides promoted immune response in juvenile shrimps by modulating hemolymph immune enzyme activities and immune-related gene expression [16]. Similarly, we here observed that a humoral immune response might be enhanced in SDP-supplemented pigs, as indicated by the increased serum concentrations of IL- 6 and TNF- $\alpha$. Furthermore, it has been demonstrated that sIgA acts as the first-line defense barrier in protecting the intestinal epithelium from enteric toxins and pathogens by agglutinating them and facilitating their clearance by peristaltic and mucociliary movements [29]. In the present study, SDP supplementation activated the intestinal mucosal immunity according to the higher sIgA content in small intestine. In agreement, the gene expression of $I L-6$ and $T N F-\alpha$ were also increased in jejunal mucosa of SDP-supplemented pigs. The TLR4 signaling cascade has been demonstrated as a classic natural polysaccharide-regulated pathway [30]. In this study, feeding SDP diet significantly increased the mRNA expression levels of TLR4, TLR6 and MyD88 in jejunal mucosa, indicating that SDP may enhance the intestinal immune-response capacity after weaning via TLR4MyD88 signaling.

The weakness in digestion and absorption of nutrients in intestine are responsible for the growth retardation and diarrhea observe in weaned pigs [17]. The high ratio of villus height to crypt depth in small intestine has been regarded as a marker of the improved nutrient digestion-absorption capacity [31]. Polysaccharides have been shown to promote intestinal epithelial growth and balance gut microflora in livestock [32]. In this study, the VCR index in duodenum, jejunum and ileum of weaned pigs were increased by SDP supplementation. Consistent with the positive effect of SDP on intestinal

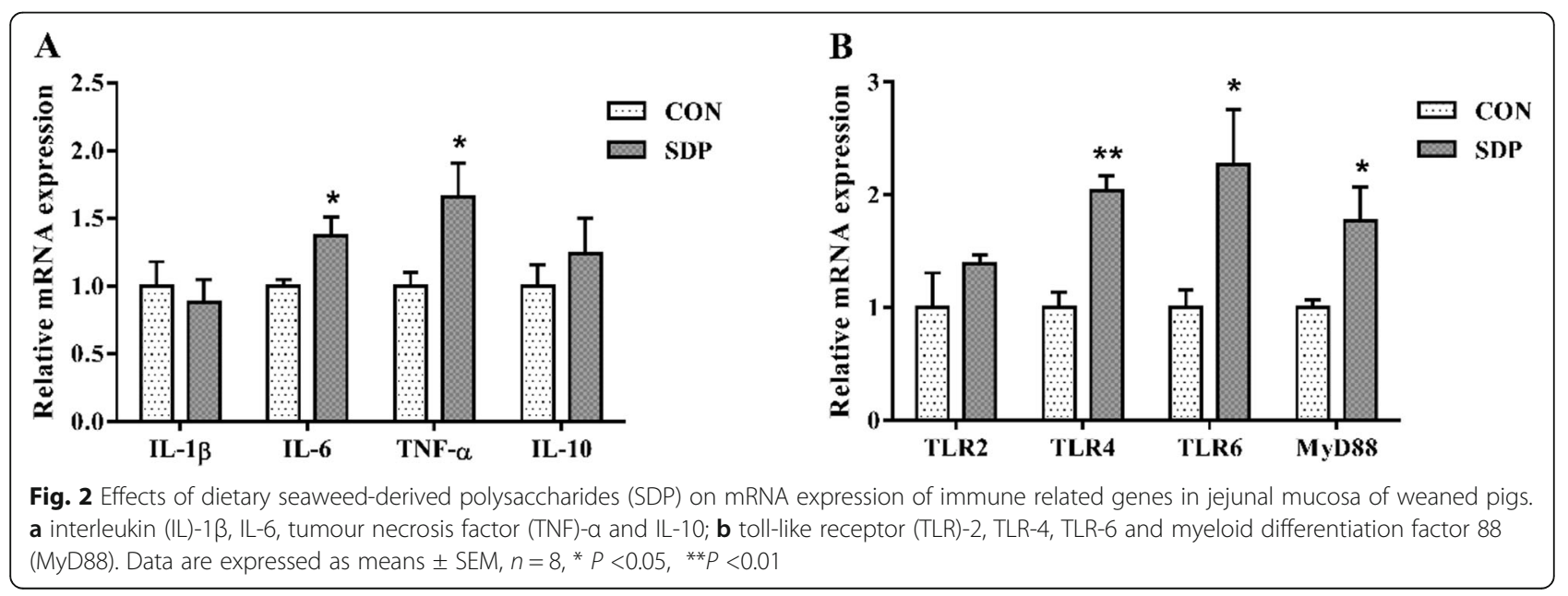



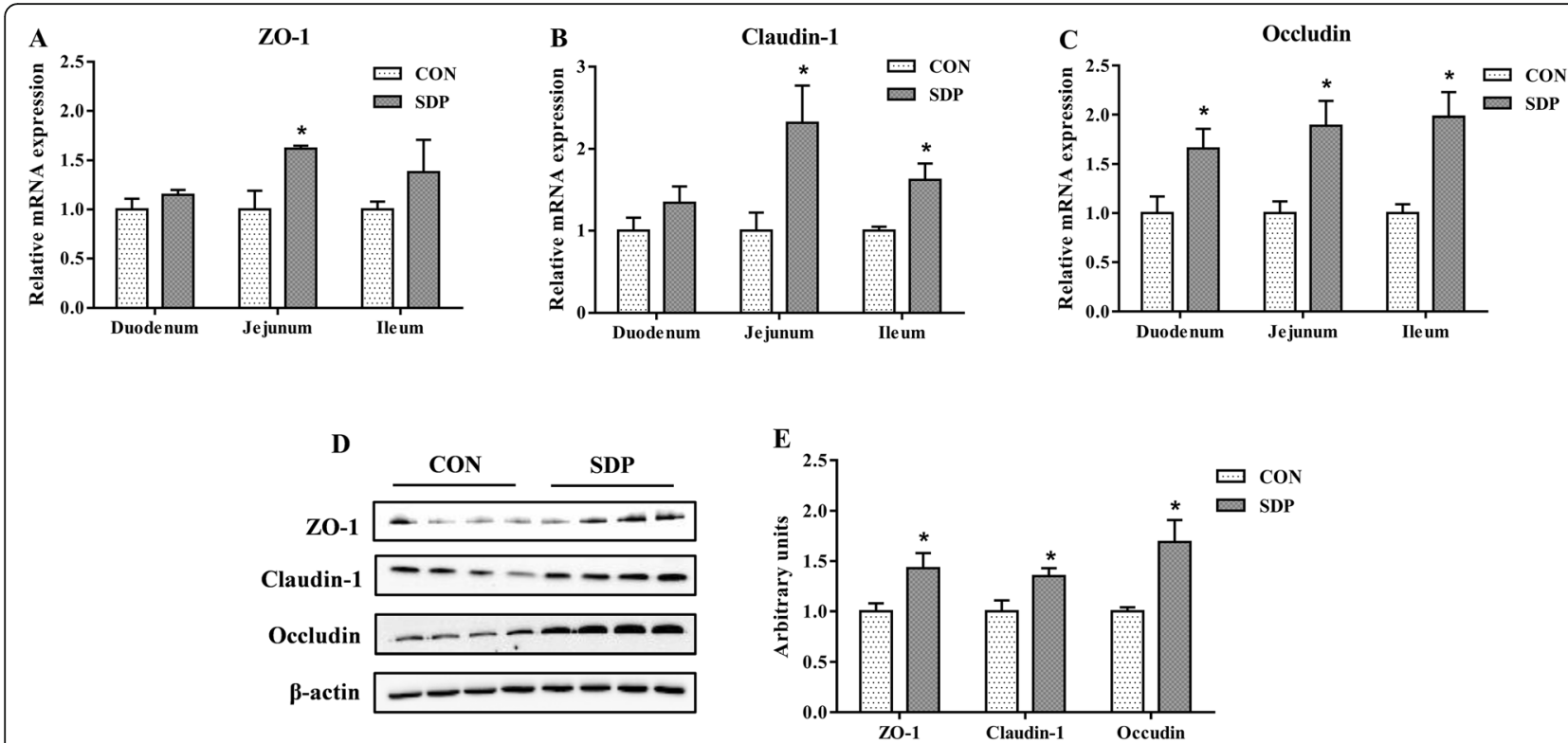

Fig. 3 Effects of dietary seaweed-derived polysaccharides (SDP) on expression levels of genes related to intestinal barrier functions in weaned pigs. a-c mRNA expression of zonula occludens protein-1 (ZO-1) (a), claudin-1(b) and occludin (c) in small intestine; $\mathbf{d}$-e representative images of immunoblotting (d) and protein expression of ZO-1, claudin-1 and occludin (e) in jejunal mucosa. Data are expressed as means \pm SEM, $n=8$, * $P<0.05$

morphology, feeding SDP diet increased the activities of lactase and maltase in the jejunum. This reflects an improvement in nutrient digestibility and may be important factors to promote the postweaning growth. Similarly, previous study suggested that dietary supplementation with seaweed extracts containing laminarin and fucoidan increased nutrient digestibility in piglets during the weaning period [33]. Furthermore, the intestinal epithelial barrier disruption, characterized by increased intestinal permeability, induces a penetration of pathogens, toxins, and antigens, negatively affecting absorption of nutrients [34]. The selectively permeable barrier is achieved by typical structural proteins of epithelial tight junction, including ZO-1, claudin-1 and occludin $[34,35]$. We found that SDP supplementation promoted jejunal structural integrity, as shown by the increased mRNA and protein expression of ZO-1, claudin-1 and occludin in jejunal mucosa of pigs. The result is consistent with the measurements of the intestinal permeability by using the blood indices. DAO and $D$-lactate levels in

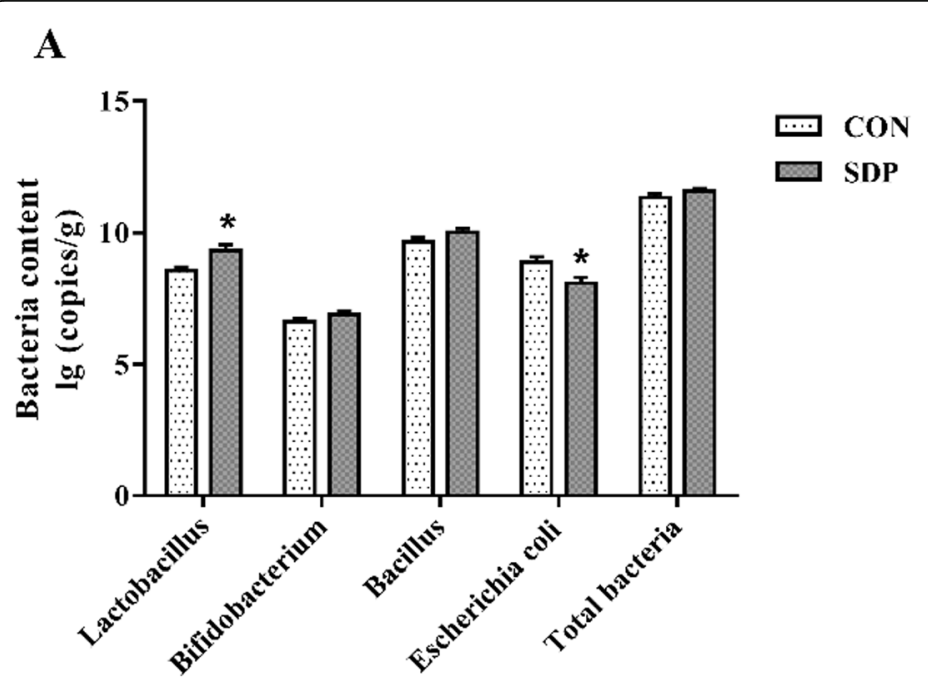

\section{B}

Fig. 4 Effects of dietary seaweed-derived polysaccharides (SDP) on intestinal microbial population and metabolites in weaned pigs. a selected microbial population in the cecum. $\mathbf{b}$ volatile fatty acid concentration in the cecum. Data are expressed as means $\pm \mathrm{SEM}, n=8,{ }^{*} P<0.05$ 
the blood were usually used as useful biomarkers for monitoring the integrity of intestinal barrier [36, 37]. In the present study, feeding SDP diet significantly decreased the serum DAO activity and $D$-lactate concentration in pigs. Taken together, these results suggested that SDP supplementation could improve the intestinal barrier function. In addition, it is well known that the signaling extent of TLR4-MyD88 pathway has closely associated with the intestinal barrier [38]. The improved integrity of intestinal barrier indicates there was decreasing risk of inflammatory bowel disease in the current study.

The intestinal microbiota, which depends mostly on non-digestible fibers and polysaccharides as energy sources, plays a vital role in many aspects of host physiology [39]. Previous studies indicated that marine polysaccharides can be efficiently catabolized and utilized by beneficial bacteria in caeco-colon [40]. In this regard, insights into the effects of SDP on intestinal ecology are of vital importance for understanding the beneficial effects of the polysaccharides. We hypothesized that Enteromorpha polysaccharides may exert beneficial effects on intestinal barrier function partially through regulating gut microbiota composition and metabolites. As expected, feeding SDP diet elevated Lactobacillus population, but reduced Escherichia coli population in the cecum of pigs. The result is similar to previous studies that the addition of fucoidan increased the lactobacilli population in the caecum of newly weaned pigs challenged with Salmonella Typhimurium [41], and seaweed extract containing laminarin and fucoidan inhibited the growth of Escherichia coli in pigs after weaning $[42,43]$. Pigs offered diets containing fucoidan had increased lactobacilli spp. in colonic digesta [44]. Furthermore, diets could influence gut microbiota community and then impact different SCFAs production [45]. The SCFAs produced by intestinal flora metabolism, mainly acetic acid, propionic acid and butyric acid, also play an essential role in improving intestinal epithelial barrier function. Butyrate acid serves as the sources of fuel for intestinal epithelial cells, which can promote the function of intestinal mucosal barrier and mitigate colitis $[46,47]$. The acetic and propionic acids are reported to enhance the tight junction barrier integrity in rat colons and cultured intestinal cells [48]. Previous study suggested that Enteromorpha prolifera polysaccharides were readily fermented by human gut microbiota in vitro and produced various SCFAs. Besides, Enteromorpha prolifera polysaccharides stimulated the population growth of intestinal Lactobacillus during fermentation process [49]. In the present study, SDP supplementation significantly increased the concentrations of acetic acid and butyric acid and Lactobacillus population in the cecal digesta, which provides a potential mechanism for SDP-improved intestinal barrier functions. Taken together, these results suggested a beneficial effect of SDP on intestinal microbial ecology and health.

\section{Conclusions}

In conclusion, our results demonstrated a potential beneficial role of SDP in improving the growth performance and intestinal health in weaned pigs, possibly via mechanisms associated with suppressing oxidative stress, improving intestinal morphology and barrier functions, and changes of the immune status and microbial fermentation. These findings indicate the potential application of SDP as a safe and effective nutritional intervention strategy to maintain gut health in neonatal mammals.

\section{Abbreviations \\ BW: Body weight; CAT: Catalase; DAO: Diamine oxidase; GSH-Px: Glutathione peroxidase; IL: Interleukin; MDA: Malondialdehyde; MyD88: Myeloid differentiation factor 88; SCFA: Short-chain fatty acid; SDP: Seaweed-derived polysaccharides; slgA: Secreted immunoglobulin A; SOD: Superoxide dismutase; T-AOC: Total antioxidant capacity; TLR: Toll like receptor; TNF- a: Tumour necrosis factor-a; VCR: Villi-crypt ratio; ZO-1: Zonula occludens-1}

\section{Acknowledgements}

Not applicable.

\section{Authors' contributions}

T.D. Zou. and J.M. You. designed research. J. Yang., X.B. Guo., and Q. He. Conducted research. T.D. Zou analyzed data and wrote the paper. J.M. You. and Z.R. Wang. reviewed the paper. J.M. You. Had responsibility for final content. The authors read and approved the final manuscript.

Funding

This study was supported by the Pig Modern Industrial Technology System Grant of Jiangxi Province (JXARS-03).

Availability of data and materials

The data produced or analyzed during the current study are available from the corresponding author by reasonable request.

\section{Ethics approval and consent to participate}

All experimental procedures used in this study were in accordance with the Chinese Guideline for Animal Welfare and approved by the Animal Care and Use Committee of Jiangxi Agricultural University.

\section{Consent for publication}

Not applicable.

\section{Competing interests}

The authors declare that they have no conflict of interest.

Received: 23 August 2020 Accepted: 11 January 2021

Published online: 10 March 2021

\footnotetext{
References

1. Peterson LW, Artis D. Intestinal epithelial cells: regulators of barrier function and immune homeostasis. Nat Rev Immunol. 2014;14:141-53.

2. Halpern MD, Denning PW. The role of intestinal epithelial barrier function in the development of NEC. Tissue Barriers. 2015;3:e1000707.

3. Smith F, Clark JE, Overman BL, Tozel CC, Huang JH, Rivier JE, et al. Early weaning stress impairs development of mucosal barrier function in the porcine intestine. Am J Physiol Gastrointest Liver Physiol. 2010;298:G352-63.

4. Cao ST, Wang CC, Wu H, Zhang QH, Jiao LF, Hu CH. Weaning disrupts intestinal antioxidant status, impairs intestinal barrier and mitochondrial function, and triggers mitophagy in piglets. J Anim Sci. 2018;96:1073-83.
} 
5. Moeser AJ, Klok CV, Ryan KA, Wooten JG, Little D, Cook VL, et al. Stress signaling pathways activated by weaning mediate intestinal dysfunction in the pig. Am J Physiol Gastrointest Liver Physiol. 2007;292:G173-81.

6. Guo Y, Zhao ZH, Pan ZY, An LL, Balasubramanian B, Liu WC. New insights into the role of dietary marine-derived polysaccharides on productive performance, egg quality, antioxidant capacity, and jejunal morphology in late-phase laying hens. Poult Sci. 2020;99:2100-7.

7. Walsh AM, Sweeney T, O'Shea CJ, Doyle DN, O'Doherty JV. Effect of dietary laminarin and fucoidan on selected microbiota, intestinal morphology and immune status of the newly weaned pig. Br J Nutr. 2013;110:1630-8.

8. Tang L, Chen Y, Jiang Z, Zhong S, Chen W, Zheng F, et al. Purification, partial characterization and bioactivity of sulfated polysaccharides from Grateloupia livida. Int J Biol Macromol. 2017;94:642-52.

9. Bouwhuis MA, McDonnel MJ, Sweeney T, Mukhopadhya A, O'Shea CJ, O'Doherty JV. Seaweed extracts and galacto-oligosaccharides improve intestinal health in pigs following Salmonella Typhimurium challenge. Animal. 2017;11:1488-96

10. Sweeney T, Meredith H, Vigors S, Mcdonnell MJ, Ryan M, Thornton K, et al. Extracts of laminarin and laminarin/fucoidan from the marine macroalgal species Laminaria digitata improved growth rate and intestinal structure in young chicks, but does not influence campylobacter jejuni colonisation. Animal Feed Sci Tech. 2017;232:71-9.

11. Walsh AM, Sweeney T, O'Shea CJ, Doyle DN, O'Doherty JV. Effects of supplementing dietary laminarin and fucoidan on intestinal morphology and the immune gene expression in the weaned pig. J Anim Sci. 2012; 90(Suppl 4):284-6.

12. Heim G, Walsh AM, Sweeney T, Doyle DN, O'Shea CJ, Ryan MT, et al. Effect of seaweed-derived laminarin and fucoidan and zinc oxide on gut morphology, nutrient transporters, nutrient digestibility, growth performance and selected microbial populations in weaned pigs. Br J Nutr. 2014;111:1577-85.

13. MCAlpine POSC, Varley PF, Flynn B, O'Doherty JV. The effect of seaweed extract as an alternative to zinc oxide diets on growth performance, nutrient digestibility, and fecal score of weaned piglets. J Animal Sci. 2012;4: 224-6.

14. McDonnell P, Figat S, O'Doherty JV. The effect of dietary laminarin and fucoidan in the diet of the weanling piglet on performance, selected faecal microbial populations and volatile fatty acid concentrations. Animal. 2010;4: $579-85$.

15. Li X, Xiong F, Liu Y, Liu F, Hao Z, Chen H. Total fractionation and characterization of the water-soluble polysaccharides isolated from Enteromorpha intestinalis. Int J Biol Macromol. 2018;111:319-25.

16. Liu WC, Zhou SH, Balasubramanian B, Zeng FY, Sun CB, Pang HY. Dietary seaweed (Enteromorpha) polysaccharides improves growth performance involved in regulation of immune responses, intestinal morphology and microbial community in banana shrimp Fenneropenaeus merguiensis. Fish Shellfish Immunol. 2020;104:202-12.

17. Zou TD, Deng CX, Wang ZR, Ye YL, You JM. Dietary alanyl-glutamine improves growth performance of weaned piglets through maintaining intestinal morphology and digestion-absorption function. Animal. 2019;13: 1826-33.

18. Livak KJ, Schmittgen TD. Analysis of relative gene expression data using real-time quantitative PCR and the $2^{-\triangle \Delta C T}$ method. Methods. 2001;25:402-8.

19. Zou T, Wang B, Li S, Liu Y, You J. Dietary apple polyphenols promote fat browning in high-fat diet-induced obese mice through activation of adenosine monophosphate-activated protein kinase alpha. J Sci Food Agric. 2020;100:2389-98.

20. Wang W, Chen D, Yu B, Huang Z, Mao X, Zheng P, et al. Effects of dietary inulin supplementation on growth performance, intestinal barrier integrity and microbial populations in weaned pigs. Br J Nutr. 2020;124:296-305.

21. Chen H, Mao X, He J, Yu B, Huang Z, Yu J, et al. Dietary fibre affects intestinal mucosal barrier function and regulates intestinal bacteria in weaning piglets. Br J Nutr. 2013;110:1837-48.

22. Franklin MA, Mathew AG, Vickers JR, Clift RA. Characterization of microbial populations and volatile fatty acid concentrations in the jejunum, ileum, and cecum of pigs weaned at 17 vs 24 days of age. J Anim Sci. 2002;80: 2904-10.

23. Yu Y, Shen M, Song Q, Xie J. Biological activities and pharmaceutical applications of polysaccharide from natural resources: a review. Carbohydr Polym. 2018;183:91-101.
24. Tanna B, Mishra A. Nutraceutical potential of seaweed polysaccharides: structure, bioactivity, safety, and toxicity. Compr Rev Food Sci F. 2019;18: 817-31.

25. Bhattacharyya A, Chattopadhyay R, Mitra S, Crowe SE. Oxidative stress: an essential factor in the pathogenesis of gastrointestinal mucosal diseases. Physiol Rev. 2014;94:329-54.

26. Yin J, Wu MM, Xiao H, Ren WK, Duan JL, Yang G, et al. Development of an antioxidant system after early weaning in piglets. J Anim Sci. 2014;92:612-9.

27. He L, He T, Farrar S, Ji L, Liu T, Ma X. Antioxidants maintain cellular redox homeostasis by elimination of reactive oxygen species. Cell Physiol Biochem. 2017:44:532-53.

28. Kharrazi H, Vaisi-Raygani A, Rahimi Z, Tavilani H, Aminian M, Pourmotabbed T. Association between enzymatic and non-enzymatic antioxidant defense mechanism with apolipoprotein E genotypes in Alzheimer disease. Clin Biochem. 2008:41:932-6.

29. Pabst O. New concepts in the generation and functions of IgA. Nat Rev Immunol. 2012;12:821-32.

30. Xie X, Ma L, Zhou Y, Shen W, Xu D, Dou J, et al. Polysaccharide enhanced NK cell cytotoxicity against pancreatic cancer via TLR4/MAPKs/NF-KB pathway in vitro/vivo. Carbohydr Polym. 2019;225:115223.

31. Biasato I, Renna M, Gai F, Dabbou S, Meneguz M, Perona G, et al. Partially defatted black soldier fly larva meal inclusion in piglet diets: effects on the growth performance, nutrient digestibility, blood profile, gut morphology and histological features. J Anim Sci Biotechnol. 2019;10:12.

32. Rattigan R, Sweeney T, Maher S, Thornton K, Rajauria G, O'Doherty JV. Laminarin-rich extract improves growth performance, small intestinal morphology, gene expression of nutrient transporters and the large intestinal microbial composition of piglets during the critical post-weaning period. Br J Nutr. 2020;123:255-63.

33. O'Shea CJ, McAlpine P, Sweeney T, Varley PF, O'Doherty JV. Effect of the interaction of seaweed extracts containing laminarin and fucoidan with zinc oxide on the growth performance, digestibility and faecal characteristics of growing piglets. Br J Nutr. 2014;111:798-807.

34. Suzuki T. Regulation of intestinal epithelial permeability by tight junctions. Cell Mol Life Sci. 2013;70:631-59.

35. Krug SM, Schulzke JD, Fromm M. Tight junction, selective permeability, and related diseases. Semin Cell Dev Biol. 2014;36:166-76.

36. Kamei H, Hachisuka T, Nakao M, Takagi K. Quick recovery of serum diamine oxidase activity in patients undergoing total gastrectomy by oral enteral nutrition. Am J Surg. 2005;189:38-43.

37. Nielsen C, Lindholt JS, Erlandsen EJ, Mortensen FV. d-lactate as a marker of venous-induced intestinal ischemia: an experimental study in pigs. Int J Surg. 2011;9:428-32.

38. Hackam DJ, Good M, Sodhi CP. Mechanisms of gut barrier failure in the pathogenesis of necrotizing enterocolitis: Toll-like receptors throw the switch. Semin Pediatr Surg. 2013;22:76-82.

39. Xu X, Xu P, Ma C, Tang J, Zhang X. Gut microbiota, host health, and polysaccharides. Biotechnol Adv. 2013;31:318-37.

40. Wang $X$, Wang $X$, Jiang H, Cai C, Li G, Hao J, et al. Marine polysaccharides attenuate metabolic syndrome by fermentation products and altering gut microbiota: An overview. Carbohydr Polym. 2018;195:601-12.

41. Sweeneya T, Dillon S, Fanning J, Egan J, O'Shea CJ, Figat S, et al. Evaluation of seaweed-derived polysaccharides on indices of gastrointestinal fermentation and selected populations of microbiota in newly weaned pigs challenged with Salmonella Typhimurium. Animal Feed Sci Tech. 2011;165: 85-94.

42. O'Doherty JV, Dillon S, Figat S, Callan JJ, Sweeney T. The effects of lactose inclusion and seaweed extract derived from Laminaria spp. on performance, digestibility of diet components and microbial populations in newly weaned pigs. Animal Feed Sci Tech. 2010;157:173-800.

43. Leonard SG, Sweeney T, Bahar B, Lynch BP, O'Doherty JV. Effects of dietary seaweed extract supplementation in sows and post-weaned pigs on performance, intestinal morphology, intestinal microflora and immune status. Br J Nutr. 2011;106:688-99.

44. Lynch MB, Sweeney T, Callan JJ, O'Sullivan JT, O'Doherty JV. The effect of dietary Laminaria-derived laminarin and fucoidan on nutrient digestibility, nitrogen utilisation, intestinal microflora and volatile fatty acid concentration in pigs. J Sci Food Agric. 2010;90:430-7.

45. Requena T, Martinez-Cuesta MC, Pelaez C. Diet and microbiota linked in health and disease. Food Funct. 2018;9:688-704. 
46. Morrison DJ, Preston T. Formation of short chain fatty acids by the gut microbiota and their impact on human metabolism. Gut Microbes. 2016;7: 189-200.

47. Peng L, Li ZR, Green RS, Holzman IR, Lin J. Butyrate enhances the intestinal barrier by facilitating tight junction assembly via activation of AMP-activated protein kinase in Caco-2 cell monolayers. J Nutr. 2009; 139:1619-25.

48. Suzuki T, Yoshida S, Hara H. Physiological concentrations of short-chain fatty acids immediately suppress colonic epithelial permeability. Br J Nutr. 2008; 100:297-305.

49. Kong Q, Dong S, Gao J, Jiang C. In vitro fermentation of sulfated polysaccharides from E. prolifera and L. japonica by human fecal microbiota. Int J Biol Macromol. 2016;91:867-71.

Ready to submit your research? Choose BMC and benefit from:

- fast, convenient online submission

- thorough peer review by experienced researchers in your field

- rapid publication on acceptance

- support for research data, including large and complex data types

- gold Open Access which fosters wider collaboration and increased citations

- maximum visibility for your research: over $100 \mathrm{M}$ website views per year

At $\mathrm{BMC}$, research is always in progress.

Learn more biomedcentral.com/submissions 